\title{
Eating rate by sheep of mature, dry subterranean clovers
}

\author{
XR Wang 1, SK Baker 1, 2, 3, DB Purser 2 \\ IFaculty of Agriculture, The University of Western Australia, Nedlands WA $6009 ;{ }^{2}$ CSIRO Division of Animal \\ Production, Private Bag PO Wembley, WA 6014 ; ${ }^{3}$ Centre for Legumes in Mediterranean Agriculture. \\ The University of Western Australia, Nedlands, WA 6009, Australia
}

Eating rate by sheep differs among cultivars of subterranean clover in the vegetative stage of growth (Dynes et al, 1993, Proc N Z Soc Anim Prod, 53, 7-9). Bite weight (g DM/bite) was negatively associated with eating rate, and bite rate (bites/min) increased linearly as the ratio of leaf to petiole increased. In short-term tests of eating rate the numbers of bites made in the first and second minutes were similar, but as the clovers matured the numbers of bites made in the second minute were progressively fewer than the numbers made in the first minute (Wang et al, 1994, Proc Aust Soc Anim Prod, $20,422)$. This suggests that as plants mature eating rate may be limited by plant characters. The objective of this study was to determine the relationship between eating rate and morphological, physical or chemical characters of mature, dry subterranean clovers.

Four cultivars of mature, dry subterranean clover (Trifolium subterraneum), Trikkala, Dinninup, Daliak and Dalkeith, were harvested from field plots and separated into leafenriched ('leaf') and stem-enriched ('stem') fractions by sieving. Eating rate was tested indoors with 6 mature, merino wethers housed in individual pens and fed a ration of wheaten hay, lupins and supplementary minerals (88: $10: 2)$. The ration $(900 \mathrm{~g} \mathrm{DM} / \mathrm{d})$ was offered in equal meals at 09:00 and 16:00 hours. A $12 \times 12$ latin square design was used, in which each sheep was offered twice each of the 4 genotypes $\times 3$ materials ('leaf', 'stem' and unfractionated material). The tests commenced at 13:00 hours each day for 6 days. Each material $(150 \mathrm{~g})$ was offered to the sheep for 3 minutes and the residue was then weighed. The number of chews was determined from the jaw movements during eating in video recordings. The energies require to shear or compress the material were determined as described by Baker et al (1993, Proc XVII Int Grassld Congr, 592-593).

Multiple regression was used to determine the association between eating rate (ER $\mathrm{g} \mathrm{DM} / \mathrm{min}$ ), and a range of plant characters : the energy required to compress (CE $\mathrm{KJ} / \mathrm{kg} \mathrm{DM}$ ) or shear (SE KJ/m²) the material, the proportion of leaf $(\mathrm{L} \%)$ or stem (S\%) in the materials and the sugar content of each material ( $S G \mu \mathrm{g} / \mathrm{ml}$ ). Cultivar (C) was included as a categorical factor to account for unidentified characters of the plant material that might influence eating rate. The model used was an additive one as follows : $E R=$ constant $(C T)+$ chews $/ g D M$ $(C W)+S E+C E+C+L+S+S G$. The only factor that contributed significantly to explaining variation in eating rate was the number of chews/g DM : ER $=18.00-1.35 \mathrm{CW}$ $(r=0.81, n=144, P<0.05)$. In a second model, $\mathrm{CW}=\mathrm{CT}+\mathrm{C}+\mathrm{SE}+\mathrm{CE}+\mathrm{L}+\mathrm{S}+\mathrm{SG}$, variation in the number of chews/g DM was explained best by the proportion of leaf in the material and the energy required to compress the material : $\mathrm{CW}=0.80-0.07 \mathrm{~L}+0.7 \mathrm{CE}$ $(r=0.60, n=144, P<0.05)$.

When feed is freely accessible, eating rate depends on the rate at which the animal can masticate the feed, moisten it adequately with saliva and swallow it (Hogan et al, 1987, 'Temperate pastures : their production, use and management' CSIRO Melbourne, 317327 ). The function of mastication, or chewing during eating, is to reduce long forage to a size that can be incorporated into a bolus and swallowed (Ulyatt et al, 1986, Proc Sixth Int Symposium on Ruminant Physiology, Englewood Cliffs, NJ, Prentice-Hall, 489-515). The results from this experiment indicate that when subterranean clovers are mature and dry eating rate is limited by the number of chews $/ g$ DM during mastication, and this in turn is determined by the proportion of leaf in the material and by the energy required to compress the material. This suggests that when mature, dry subterranean clovers contain a high proportion of leaf they are easier to compress into a bolus and swallow.

This work has been funded partially by Australian woolgrowers through the International Wool Secretariat. 